\title{
William B. Arveson: A Tribute
}

\section{Daniel Markiewicz and Palle E. T. Jorgensen, Coordinating Editors}

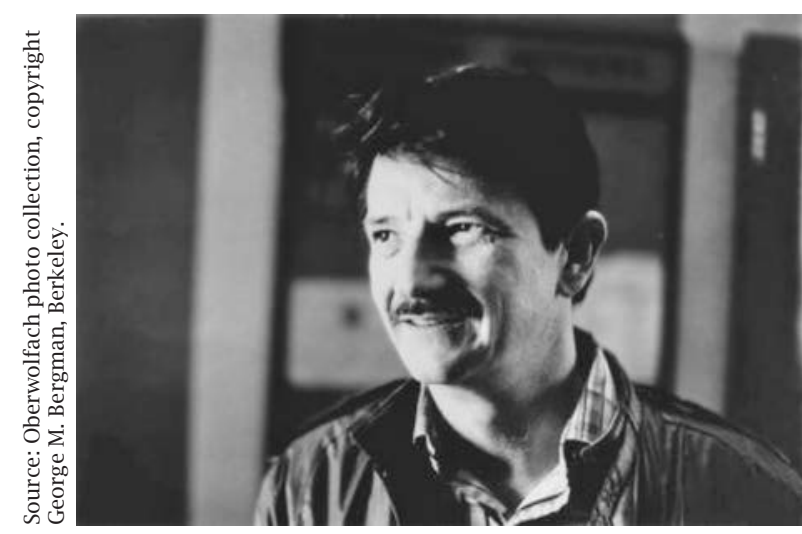

William B. Arveson

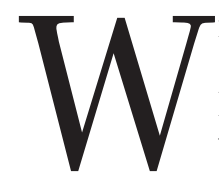

illiam Arveson's work has been extraordinarily influential, and it is known to everyone in functional analysis and in operator algebras. Bill's career spanned UCLA, Harvard, and (since 1968) UC Berkeley, where he had twenty-nine $\mathrm{PhD}$ students and also mentored several postdocs. As we prepared this tribute we were struck by the sheer number of spontaneous notes or comments from mathematicians who felt personally inspired by his papers in the beginning of their careers.

Functional analysis and operator algebras owe much to Hilbert's and von Neumann's pioneering visions for a rigorous mathematical foundation of quantum mechanics (Hilbert's Sixth Problem [19]; see also [8]). Two other areas motivated these subjects from the start: ergodic theory and the study of unitary representations of groups,

Daniel Markiewicz is senior lecturer in the Department of Mathematics at Ben-Gurion University of the Negev. His email address is danie1m@math.bgu .ac. 11.

Palle E. T. Jorgensen is professor of mathematics at the University of Iowa. His email address is pa11e-jorgensen@ ui owa. edu.

DOI: http://dx.doi.org/10.1090/noti1264 especially the Lie groups arising in relativistic quantum theory.

The noncommutativity that lies at the heart of quantum theory exerted great fascination for Bill. His work was often inspired by problems from physics, but this was by no means the full story. Over decades, Bill pioneered making sense of deep questions regarding noncommutative harmonic analysis, operator theory, and operator algebras. These developments had great impact on modern analysis and propagated to other fields. Bill produced many "pure" theorems of unusual elegance and striking beauty, and we refer the reader to two recent survey articles on some of his many contributions to mathematics: [7], [13].

In the following we include several articles from Bill Arveson's colleagues written especially for this tribute. In order to comply with the space assigned by the editors, the articles have been shortened substantially. For the full version see www. math. bgu. ac. i1/ danie $7 \mathrm{~m} / \mathrm{share} /$ arvesonmemorial-article.pdf.

\section{Kenneth R. Davidson}

Bill Arveson completed his doctorate in 1964 at UCLA under the supervision of Henry Dye. After an instructorship at Harvard, Bill started a long career at the University of California, Berkeley. I was a student of his in the early to mid-1970s. Bill was still young but already had had a strong influence on operator theory and operator algebras. The influence of this early work continued to grow in the following decades.

Arveson's work was deep and insightful and occasionally completely revolutionary. When he attacked a problem he always set the problem in a general framework and built all of the infrastructure needed to understand the workings.

Kenneth R. Davidson is University Professor in the Department of Pure Mathematics of the University of Waterloo, Canada, a Fellow of the Royal Society of Canada, and a Fields Institute Fellow. His email address is krdavids@uwater1oo.ca. 
This perhaps is the reason that his influence has been so pervasive in many areas of operator theory and operator algebras.

I will skip ahead in time, passing by many important results, to the current century. Arveson tackled the problem of multivariable commutative operator theory. The ideas of dilation theory, now well established, suggest that one should understand the universal operator algebra determined by appropriate algebraic and norm constraints. A number of authors in the noncommutative setting had observed that a row contractive condition was proving to be much more amenable than insisting that individual generators be norm one. Bill applied this to an $n$-tuple of commuting operators. The canonical model that he developed was the space of multipliers on symmetric Fock space. This space turned out to have other remarkable properties. Arveson showed that it was a reproducing kernel Hilbert space of functions. David Pitts and I showed that it was a complete Nevanlinna-Pick kernel, and Agler and McCarthy showed that it was the universal complete NP kernel. These three results came from different directions but served to make operator theory on this space a rich venue for analysis and algebra.

Bill went on to write a long series of papers on this operator algebra. He introduced many ideas from commutative algebra into the program. He developed a notion of curvature as a key invariant for commuting row contractions and many other ideas. He made an important conjecture which has generated a tremendous amount of work by many authors. As with his earlier work, he had the good taste, the vision, and the mathematical power to establish a powerful new approach to an important problem.

This is his legacy, a deep and powerful vision of operator theory and operator algebras as an integrated whole. He brought ideas from function theory, harmonic analysis, commutative algebra, geometry and physics to bear on problems in operator theory and operator algebras (two areas I am sure that he considered as one) and produced works of art that have attracted almost every practitioner of this subject at some time. He has had a profound impact, and this impact will continue for a long time to come.

It is my honor to have been a student of Bill's. His work influenced me more than most, since most of my work, traced to its roots, goes back to Bill in some way. I am glad that I had the privilege to know him.

\section{Ronald G. Douglas}

Ronald G. Douglas is Distinguished Professor of mathematics at the Texas A\&M university. His email address is rdoug1as@math.tamu.edu.

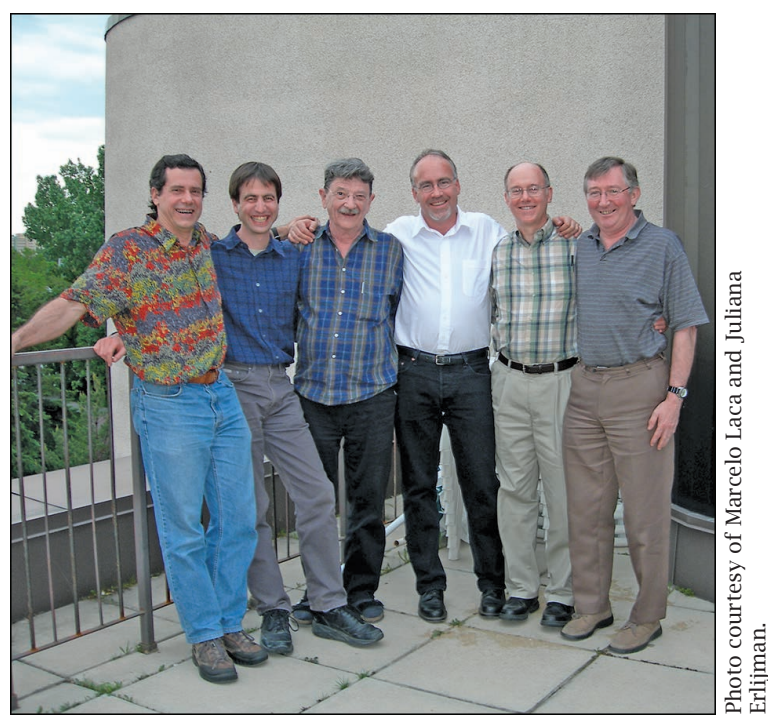

Bill Arveson and some of his students at COSy 2006. From the left: Marcelo Laca, Ilan Hirshberg, (Bill), Michael Lamoureux, Kenneth R. Davidson, and Donal P. O'Donovan.

In January 1965, after giving a ten-minute talk at the annual American Mathematical Society meeting, held that year in Denver, a graduate student came up to me and asked a question. I don't recall what he asked, but I do remember the event because it was the first time I met Bill, and our mathematical careers became intertwined from that point on. We became, and remained, strong friends and colleagues over the next almost fifty years.

In the early seventies, I collaborated with Larry Brown and Peter Fillmore to produce the body of results usually known as BDF theory. Classes of operator algebra extensions were made into an abelian group which could be calculated, resulting in some then rather surprising results in operator theory. I had many discussions with Bill in the middle seventies in which he wrestled with these ideas, trying to fit them into his context. No surprise-he did! He saw the bigger picture relating the group structure to certain questions in operator algebras involving completely positive maps and nuclearity.

The machinery connected with BDF theory that Bill provided helped extend the ideas and provide the extension framework for Guennadi Kasparov's KK-theory. Further, revolutionary development of these ideas by Alain Connes, Kasparov, and many others led to the Special Year at MSRI in Berkeley in 1984-85. By this point, Bill was well on his way to inviting an outstanding group of young mathematicians into the field, and his seminar was a must for everyone interested in linear analysis, both as a speaker and as an attendee. Bill also participated in the social life surrounding the program at MSRI. On one Friday evening, he offered 


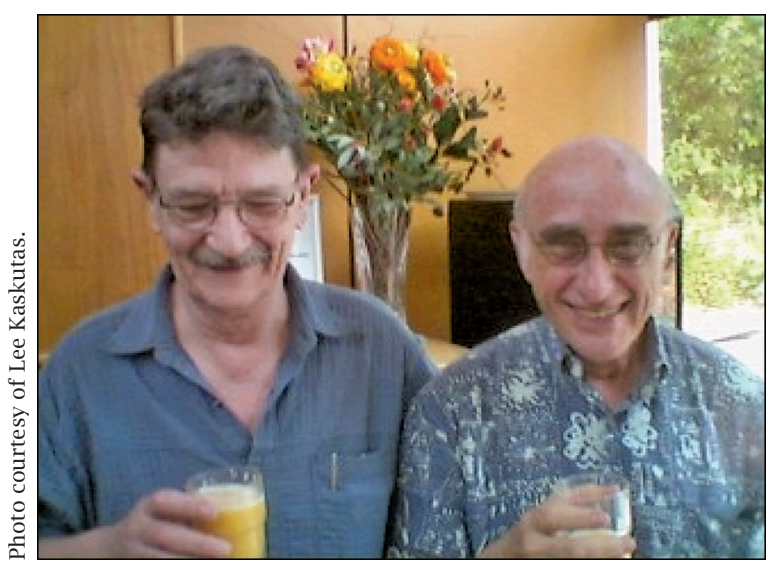

Bill Arveson with Edward Effros.

to show a group of perhaps ten, "his San Francisco." After dinner and wandering through the North Beach area, we ended up at Carol Doda's club, where she invited Bill on stage to join her. Bill didn't disappoint.

While attending a conference at Berkeley in February 2003 honoring Donald Sarason, Bill told me that he had come upon a problem he wanted to discuss with me. During the rest of that year and at conferences that December in Bangalore and Chennai, we discussed his problem. He was trying to get $C^{*}$ - or quantum models for projective varieties in $\mathbb{C}^{n}$. He sought to show that the closure of a homogeneous polynomial ideal in the symmetric Fock space is essentially normal; that is, the crosscommutators of polynomial multipliers and their adjoints are compact. (Actually he conjectured that they are in the Schatten-von Neumann $p$-class for $p$ greater than $n$.) He was able to show that this was the case for homogeneous ideals generated by monomials but not in general. I became intrigued and was able to extend his results modestly. Both Bill and I announced, at different times, proofs of the conjecture, which turned out to be incomplete. In talks Bill spoke of the witch's curse on this problem, and indeed at least one other incorrect proof has been announced since then. The question is deep and has attracted the attention of researchers around the world, but the general case remains open.

\section{Edward G. Effros}

The functional analysts at UCLA were devastated by the news that Bill had passed away. He was one of the key figures in the development of noncommutative functional analysis and its applications to a wide range of mathematical disciplines. I will

Edward G. Effros is Professor Emeritus and Distinguished Research Professor of mathematics at UCLA. His email address is ege@math.ucla.edu. largely restrict my remarks to several of Bill's papers on linear spaces of operators.

One of Bill's most influential discoveries was that one could develop a theory of boundaries for the operator algebraic analogues of function algebras [1]. His key observation was that linear spaces of operators have a hidden matricial structure that must be incorporated into the theory. This rests upon the fact that a matrix of operators is again an operator, and thus the matrices over an operator space form again an operator space. The ordering and norms of such matrices are essential parts of the relevant structure and must be acknowledged by the morphisms, i.e., by the completely positive and completely bounded operators.

Although complete positivity had been investigated earlier by Sz. Nagy, Stinespring, and Umegaki, Bill was the first to appreciate the power of these notions. The crowning achievement of his early theory were analogues of the Hahn-Banach theorem for completely bounded and for completely positive mappings (put in its final form by Wittstock [20]). He used this theory to prove important results about matrix numerical ranges.

Soon the young operator/functional analysts jumped on the matrix ordered version of Bill's theory (operator systems), and before very long the injective (or semidiscrete) von Neumann algebras were characterized as being the hyperfinite von Neumann algebras (work by Connes, Choi, Lance, and me). Of course, there were many other directions to be pursued, and within a few years the nuclear $C *$-algebras were determined (Choi and me, and some parallel work by Kirchberg), and lifting theorems were proved (relevant to KK theory).

Owing to Ruan's axiomatization of the operator spaces (the quantized Banach spaces [17]), the full significance of Bill's approach to matrix norms is now also understood. This has enabled researchers to find noncommutative analogues of many of the notions of Banach space theory (see [9], [16]). Very recently, the matrix ordered operator systems have seen an upswing of interest, due to the work of Vern Paulsen and his colleagues [15]. Yet another application of these ideas may be found in the abstract characterization of the nonself-adjoint unital operator algebras [6]. This provides an elegant framework for Arveson's original investigations.

Bill's interests ranged over a wide range of subjects, and he influenced several generations of mathematicians. A particularly intriguing example of this work was his theory of continuous tensor products, which was also pursued by Bob Powers and then by Boris Tsirelson. What was truly remarkable about Bill was that his productivity never declined throughout his mathematical career. He was always ready to tackle a completely new area. This is illustrated by some of his last papers, 
which are concerned with quantum information theory.

Although I have never worked on noncommutative boundary theory, I would be remiss if I did not recount one of Bill's most spectacular recent results. Nearly forty years before, he had posed the problem of determining if operator systems have sufficiently many boundary representations. Important contributions had been made by a number of individuals, including Dritchel and McCulloch, Muhly and Solel, as well as Ozawa. In [3] he finally succeeded in proving the result for separable operator systems by using delicate direct integral techniques. This is an old-fashioned technology (dear to my Mackey heritage) that might not have been appreciated by his younger colleagues.

Upon the appearance of that work, I couldn't resist writing to him that he "had shown all those young whippersnappers a thing or two." He gleefully replied that he shared that opinion, and then he characteristically sent me a fascinating paper on operator systems on finite-dimensional Hilbert spaces [4]. I am only just beginning to realize its importance.

Having summarized so much of Bill's professional accomplishments, I would like to add a final personal memory that summarizes how nonmathematicians viewed Bill. I was with my family at Victoria Station in London, probably in the late 1980s, awaiting the train to a math conference somewhere in the UK when we bumped into Lee (Bill's wife) and Bill, who were en route to the same meeting. We all spoke for a while, then moved on so that we could get a bite to eat. Our teenage daughter asked how we knew these two people, and I mentioned that Bill was a mathematician. Having met many of my colleagues over the years, she looked totally shocked and said, "That guy seems much too cool to be a mathematician!"

Bill, you will be irreplaceable.

\section{Richard V. Kadison}

Bill and I met during his graduate student days at UCLA. He reminded me of that, with a smile, on a few occasions each time I said that we had met during the so-called "Baton Rouge Conference" (at LSU in March of 1967). After two or three corrections, much to Bill's amusement each time, I finally got that straight (I'm a slow learner, but then I retain it tenaciously). As I was just noting, when I first met Bill at that Baton Rouge conference the year was 1967, the same year in which Bill's great paper in Amer. J. Math. appeared. We'll have more to say about that paper at a later point. It was clear to me that Bill was a very smart young

Richard V. Kadison is Gustave C. Kuemmerle Professor of Mathematics at the University of Pennsylvania and a member of the US National Academy of Sciences. His email address is kadison@math. upenn. edu.

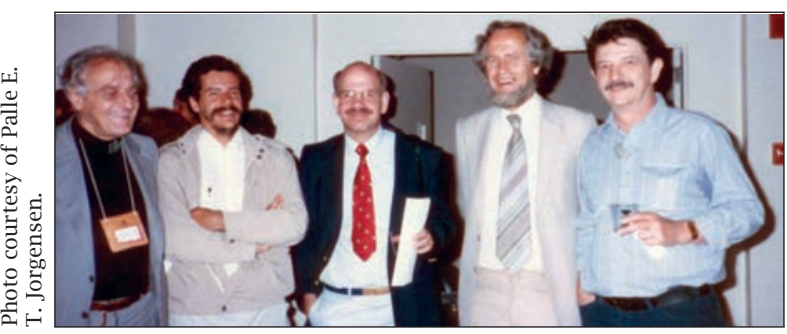

From the left: Daniel Kastler, Marcelo Laca, Paul Muhly, Hans Borchers and Bill Arveson at a conference at the University of lowa in 1985.

mathematician. What I hadn't known, until we had that time to talk to one another, was that Bill had a personality that was very congenial to my own way of doing and thinking about things. Bill was articulate and clear, with the kind of humor that I enjoy. He had a candor, at least when talking with me, that I appreciated. It wasn't "kick-in-the-shins" candor, the kind that hurts people without much extra purpose. When I listen to some people who pride themselves on being "candid," I feel that they are deriving at least as much pleasure from being cruel as from being "forthright." I never detected one scintilla of cruelty in Bill's interaction with people. What one could observe about Bill was that he had an abundance of what the young people these days call "cool." At a conference in England (Durham, I think) that Bill, Ed Effros, and I were attending, I talked to Rita Effros during a lunch break. She reported that her son, then a youngster, had remarked to her the preceding evening that "Bill Arveson was the coolest mathematician he had met." At the same moment in which she told me that, she realized that she might have offended me by not saying that her young son thought that I was cool as well. Now, Rita is as sweet and kind as they come, to which everyone who knows her will attest. But level of coolness is not one of the axes in my personality description on which people are prepared to place a mark. Bill's "cool credentials" are, however, unassailable. ...

At this point, we've come full circle; we are back to Bill's 1967 Amer. J. Math. paper [5]. In section 4.3 of that paper, Bill speaks of "determinants" in a von Neumann algebra setting. He cites the "determinant" that Bent Fuglede and I introduced [10], [11] and used to answer a question we had asked ourselves: Must a generalized nilpotent operator in a $\mathrm{II}_{1}$ factor have trace 0 ? We proved, using that determinant, that the trace of each operator lies in the closed convex hull of the spectrum of the operator, which of course provides a positive answer to the question about generalized nilpotents. Bill notes that our determinant applies to more general circumstances than the $\mathrm{II}_{1}$ factor case without the least difficulty; statements, definitions and proofs, remain virtually unchanged. One has, for example, the extension 
to general, finite von Neumann algebras, where a fixed tracial state is used in place of the trace itself in the factor. Using this determinant, Bill states and proves a generalization of the Hadamard determinant inequalities [12], mentioned in the report to Is Singer. It involves the tracial state and a conditional expectation that "lifts" it. This occurs in section 4.3. In section 4.4, the final section of Chapter 4, Bill formulates an extension of Jensen's inequality in terms of Bill's "subdiagonal algebras," the determinant, a conditional expectation onto the "diagonal" of the subdiagonal algebra, and a tracial state that lifts it.

In some inexplicable way, my browsing in Bill's paper back near the time it first appeared had been, at most, superficial.

It's not too daring to predict that he will be in the thoughts of many mathematicians for many years to come.

\section{Marcelo Laca}

It is difficult for me to imagine the world without Bill Arveson, mathematician, mentor, and friend. The recognition that he left behind an extremely rich mathematical legacy, both in print and in the minds of those he inspired, is only a partial consolation. He also left behind a wonderful network of friends and colleagues who will remember him fondly and miss him sorely. I had the privilege of doing my $\mathrm{PhD}$ with him in a period that shaped the rest of my life, and I would like to take this opportunity to reminisce and give a glimpse of what it was like to have Bill as an advisor and also to share some of his advice. Other aspects of Bill's professional life and his many contributions to mathematics are described elsewhere by others.

I am convinced that when Bill did mathematics, he just thought differently from everyone else I know; his was a very intimate thought process that was not complete and could not be shared until he had the perfect way of presenting the big picture, frame and all. Many of his papers became hugely influential in the field, and for all I know, many others are just awaiting rediscovery to achieve a similar fate, for Bill's ideas are deep and timeless. His work is all the more impressive considering that he worked almost exclusively by himself and that he only published what met his high standard. His research touched upon many areas. One common thread was that he preferred to deal with challenging problems, another was the principle that to be properly understood, problems should be put in operator algebraic terms. Only once or twice I got the feeling that something I was saying was news to him, but, in any case, the interval between "that cannot be true" and "I

Marcelo Laca is professor of mathematics at the University of Victoria, Canada. His email address is 1aca@uvic.ca. see" was never long enough to enjoy. He was very generous with credit and with his ideas. Embedded in his explanations there were often priceless jewels of his original insight, which he simply gave away as part of his approach to the subject. These keep cropping up once and again in my mathematical life, evoking no small amount of admiration, gratitude, and nostalgia.

\section{Paul S. Muhly}

Ihad the wonderful good fortune to spend the 197778 academic year on sabbatical at the University of California at Berkeley. It was an extraordinarily stimulating experience, but my most vivid memories are from the times I spent talking with Bill Arveson. Among the many things we discussed were his papers, "Subalgebras of $C *$-algebras I \& II" [1], [2]. I was already very familiar with them. Indeed, I had spent a lot of time studying them. I found them full of inspiration, and after more than forty years I still do.

So I was taken aback, early in our discussions, when Bill expressed disappointment that "Subalgebras I" had not received more recognition. It was Bill's most heavily cited paper and it continues to be No. 1, with almost one hundred more citations on MathSciNet than the runner-up. One might think, therefore, that Bill was being greedy. He was not, and I would like to take this opportunity to explain why.

Bill wrote [1], [2] in order to set the stage for studying general, not-necessarily-self-adjoint operator algebras. He drew inspiration from several sources. First there was the seminal work of Kadison and Singer [14]. This was the first paper dedicated to studying nonself-adjoint operator algebras. Their objective had been to classify algebras of operators which are infinite-dimensional analogues of the algebra of upper-triangular $n \times n$ matrices. Bill also gained inspiration from the dilation theory that was due in large part to Sz.-Nagy [18]. Owing to the contributions of many function theoretically oriented functional analysts, dilation theory had grown into a model theory for arbitrary operators on Hilbert space. And he was inspired by developments in the theory of function algebras. This theory had arisen, in large part, to provide a functional analytic treatment of spaces of analytic functions that arise in harmonic analysis and in approximation theory. There were already very close ties between the theory of function algebras and the model theory stemming from the dilation theory of Sz.-Nagy.

I was delighted that Bill solved the problem and that finally the central thesis of [1] had been fully vindicated. Since the appearance of

Paul S. Muhly is professor of mathematics and statistics at the University of Iowa. His email address is pau1muh7y@uiowa. edu. 
[3], there has been an uptick in the interest in [1], and I suspect-indeed, I fervently hopethat the program that Bill initiated in it will flourish for years to come. In addition to being the source of great mathematics, "Subalgebras of $C^{*}$-algebras" will serve as a monument to Bill's unswerving perseverance, from which we may all draw inspiration.

\section{David R. Pitts}

Most chance meetings are of little consequence. But a few are life changing. I first met William Arveson in a laundromat in Berkeley in the early 1980s, and in the ensuing conversation I learned he was a mathematics professor, and he learned I was a mathematics graduate student. The circumstances amused us both. Shortly afterward, I remember thinking that would be a remarkable way to meet a thesis advisor. To my great fortune, Bill became my PhD supervisor a year or so later.

Arveson once told me that he published "when I have something to say." It wasn't until after completing my graduate studies that I began to appreciate the remarkable scope and impact of Arveson's work. I took Bill's advice and went to as many conferences as I could. At these meetings, I'd hear Arveson's name attached to an astonishing number of deep and pioneering results, some related to, but many others far removed from, what I'd studied as a graduate student. Bill truly had a lot to say!

I, along with many others, have benefited much from Bill's mathematics, mathematical leadership, guidance, and generosity. He is greatly missed.

\section{Robert T. Powers}

I have known Bill Arveson all of my mathematical life, as I first met him at the large Baton Rouge conference in March of 1967 while I was still a graduate student in physics, a student of Arthur Wightman working in quantum field theory. I remember his enthusiasm as we talked of factors, von Neumann algebras with a trivial center. At that time I was under the illusion that problems of quantum field theory would be settled by applying the techniques developing in $C^{*}$-algebras and von Neumann algebras. Over the years we saw each other many times at Berkeley, Philadelphia, and at conferences all over the world.

I should say at the start that I do not enjoy reading other people's papers. I often spend weeks trying to prove a result rather than looking it up,

David R. Pitts is professor of mathematics at the University of Nebraska-Lincoln. His email address is dpitts2@ math. un 1 . edu.

Robert T. Powers is professor of mathematics at the University of Pennsylvania. His email address is rpowers@ math . upenn. edu. and I tend to ignore work that does not have a direct bearing on what I am currently working on. For that reason I am not qualified to assess the impact of Bill's work on mathematics. But as much as I have avoided reading other people's papers, I could not avoid reading many of Bill's papers, which I not only read but studied to the point that Bill's ideas became incorporated into my own research. I was frankly jealous of one of his earlier papers on one-parameter automorphism groups that can be implemented by unitary group with positive spectrum, an idea from physics expounded in an early paper by Hans Borchers, in that I was well aware of the ideas leading up to it but kicked myself for not seeing Bill's brilliant thoughts for turning these ideas into gold.

Intellectually I know Bill died, but I still don't believe it. I know next spring I will think about visiting Bill and Lee in Berkeley or look forward to hearing that laugh of his regarding some recent development till I remember the hole that he has left. I only interacted with Bill in a fraction of his mathematical work, and I am sure others can tell similar stories about his significant influence in different areas of mathematics.

\section{Geoffrey L. Price}

In the late 1970s it was my good fortune to be a graduate student at the University of Pennsylvania, where Dick Kadison had assembled a stellar cast of operator algebraists, including Bob Powers, my thesis advisor, and where Bill and other big names in operator algebras would come to spend their sabbatical year. Although I was too shy to speak with him, it was clear from a distance that Bill was a different sort of mathematician altogether. He was the operator algebraist's answer to Jack Kerouac or Belmondo, complete with great hair, bomber jacket, sneakers, cool demeanor, and cigarette always in hand. He had a style of lecturing in the Tuesday functional analysis seminars that was more conversation than lecture, and the ease with which he brought so many ideas to bear in his presentations was breathtaking and more than a little intimidating to a graduate student.

Another of Bill's important contributions to the subject came soon after. In his first paper Powers introduced a notion of a numerical index for $E_{0}$-semigroups which can be a positive integer or infinity. He was able to show that the index was subadditive under tensor products and that it was additive for the CAR-flows. Using product systems, Bill introduced his own notion of index, which agreed with the Powers index for the CAR flows. Bill established that his index was actually additive under tensor products: $d_{\alpha \otimes \beta}=d_{\alpha}+d_{\beta}$.

Geoffrey L. Price is professor of mathematics at the US Naval Academy, Annapolis. His email address is g1p@usna.edu. 
Ten years later I had the good fortune to work long distance with Bill on a couple of projects, one of which involved the behavior of infinite tensor products of CP-semigroups of the type above. It was a thrill to work with one of my mathematical heroes. Bill would write to me what he'd thought about on a given day and would close by saying that it was time for a glass of wine and, according to him, further inspiration from his dachshund: "Last night I dreamed that Schnitzel said, 'Think symmetry stupid!', So I followed his advice and I think I found a more manageable invariant." Bill's wife, Lee, has given me his handwritten notes on that paper, and I am happy to have them here beside me.

\section{Donald E. Sarason}

Bill Arveson and I were colleagues and friends in Berkeley for forty-four years. If memory serves, I first met Bill in person in Ann Arbor when he was a Benjamin Peirce Instructor at Harvard. The occasion was one of Paul Halmos's summer operator theory get-togethers.

Bill and I had many common mathematical interests, but our modus operandi were different. My attraction was to concrete problems. Bill, in contrast, always had the global picture in view. Beyond possessing an intimate grasp of the technical aspects of his specialty, he had an uncanny insight that led him to intriguing uncharted territory, coupled with the boldness to launch an exploration.

Those who knew Bill are aware that he had a stubborn streak, a beneficial trait for anyone engaged in research. Bill's stubbornness extended beyond mathematics. As anyone of a certain age will recall, the 1960s and 1970s were tumultuous times, especially on many college campuses, including Berkeley's. One day not long after he came to Berkeley, Bill entered Sproul Plaza, the main campus entrance, while a demonstration of some kind was in progress. The police were trying to clear demonstrators out and kept telling people to move on, move on. When Bill received this order he replied, "I have a perfect right to be here." He held his ground until he was suddenly seized from behind by a very large cop and hustled off to the local jail. He did not carry enough cash to post bail, but he managed to contact our chair at the time, John Addison, who got him released. I believe no charges were pressed. Bill never backed down when he thought he was in the right.

Donald E. Sarason is Professor Emeritus of mathematics at the University of California, Berkeley. His email address is sarason@math. berkeley.edu.

\section{Erling Størmer}

Among operator algebraists, now in their seventies or eighties, the most memorable conference they ever attended was the one in Baton Rouge in Louisiana in 1967. Then many of us met for the first time and initiated lifelong friendships. Bill and I were no exceptions. Our friendship grew over the years, as we regularly met at conferences and their like, and culminated with my three one-semester visits to Berkeley after 1998, when I enjoyed his hospitality and saw him regularly on and off campus.

While Bill was very social when he was with people, he was basically more of a loner. He worked very much by himself and mostly at home. Last time I was in Berkeley, we wrote a little paper together. It was a rather special collaboration. Our discussions mostly lasted for a few minutes when he took a little time away from his home, where his charming dachshunds were waiting for him. I remember, as the highlight, when we spent a full half hour at one of the coffee shops at Berkeley campus discussing our paper. But it was really an enjoyable and pleasant collaboration.

Much more can be said about his huge mathematical production, for example his work related to mathematical physics, in particular on entanglement in quantum information theory. But I stop here, hoping that the above gives the reader a feeling for the width and depth of his mathematical contributions.

\section{Lee Ann Kaskutas}

Bill was born in Oakland. His parents divorced when he was just a year old. In his earliest years Bill was raised by his grandmother, who had come here from England. She was the first forewoman at the Levi Strauss factory in San Francisco, so was gone during the day. They lived in a house on Trask Street, and his grandmother had a lady come in to be there when Bill got home from school. Bill would walk to and from the local public grade school with a neighbor boy, who had a miniature dachshund that Bill loved to play with. Bill deeply loved his

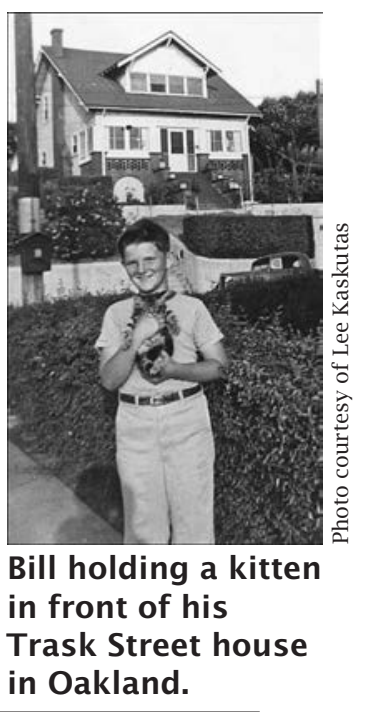

Erling Størmer is Professor Emeritus of mathematics at Oslo University, Norway. His email address is er7ings@ math. uio.no.

Lee Ann Kaskutas is a senior scientist at the Alcohol Research Group and associate adjunct professor at the School of Public Health, University of California, Berkeley. Her email address is 1kaskutas@arg.org. 


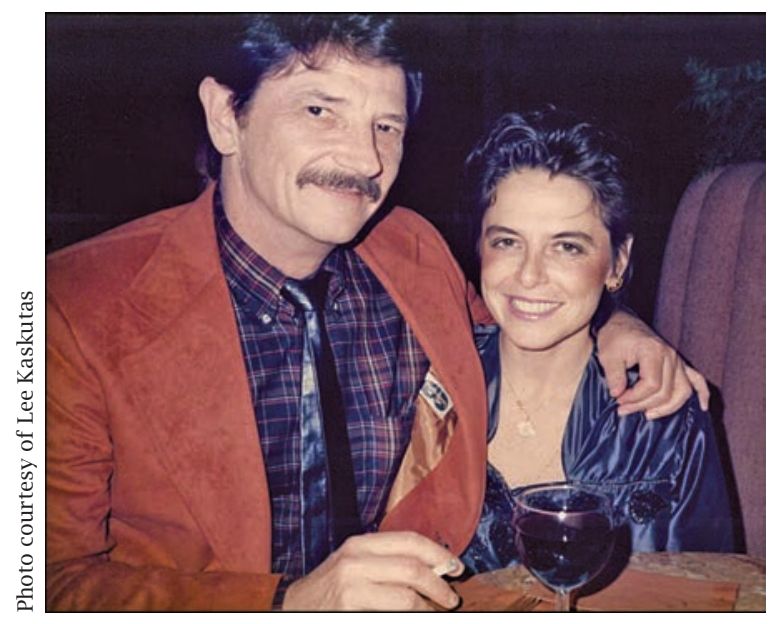

Bill and Lee at Cliff House, San Francisco, Thanksgiving Day, 1985.

grandmother and as a child did

not see much of his parents, who had separately moved to Southern California. After graduating from high school, Bill joined the navy, took a placement test, and was told he could have pretty much any job he wanted to train for. He chose to study radar technology and spent many months at navy schools on Treasure Island and also in Washington State. After his training he served in the Pacific on an aircraft carrier in the "CCC", the Command and Control Center, where he was their ace repairman. When not repairing the radar equipment, he played bridge, read, and taught himself how to play the jazz saxophone. (Bill played jazz piano too in his younger days.)

At the end of his three years of naval service, Bill took another placement test at the navy. Apparently he got the highest score that anyone had ever gotten. They asked him to stay in the navy and enter their training program for jet fighter pilots. He told me that had he done that, he would probably have become an astronaut (and now, he joked, would be an airline pilot!). He decided instead to leave the navy and try to go to college.

Bill went to Pasadena City College for two years, then took still another test, this one to compete for the two slots that are made available each year for transfers to Cal Tech. Again, his performance on the test was a big surprise to everyone, including the math professor who had to grade the math question. It seems the professor did not expect anyone to actually be able to solve the problem; he just wanted to see how they approached it. Bill solved the problem, was admitted to Cal Tech, and majored in mathematics, of course.

One day at the Naval Undersea Research Center, Bill got a call from his thesis advisor, Henry Dye, who told him to apply for the Benjamin Peirce Instructor job at Harvard. Bill was shocked. "Me?" he said. "Yes, you should apply, Bill," insisted Henry
Dye. But Bill was ambivalent, in large part because the navy had paid for his education, and he felt that he owed them. He took the issue to his boss, also a PhD-level mathematician, who told him that it would be payback enough if Bill were to thrive as an academic mathematician, training other mathematicians, and doing original mathematics research. Bill's eyes would tear up when he told me that story, because he was so grateful and impressed by the generosity expressed by the man.

Bill joined the Berkeley mathematics department in 1968 as a lecturer, became an associate professor in 1969, and a Full Professor five years later. He retired in 2003 and continued doing mathematics research until his death in November 2011.

When Bill did his mathematics research he got excited about his discoveries and might write "WOW" in big letters, plus three exclamation points, and put a box around it. I only discovered this about Bill-that he was alone but not lonely doing his work-when I went through his papers to choose something handwritten for one of the collages for his memorial service.

\section{Family $_{\text {Bill }}=$ Mathematical Family}

Bill was enormously proud of his students. He shared with me how he chose his students. He had two rules. They had to have demonstrated that they would be able to do deep, original mathematical research. But that is an obvious criterion. The second rule was that he had to like them, that they had to be nice, good people. He did not take on a new student lightly or thoughtlessly and felt it to be a lifelong commitment. Whenever possible, we would have the student over to dinner at our house when they were graduating. Bill looked forward to these dinners very much, and afterwards he loved hearing what I thought of the person, as it was often the first time we had met. I liked them all and loved some, as did he.

A memorial service honoring Bill was held on February 19, 2012, at the Berkeley Faculty Club. At the service we enjoyed French wine from Bill's wine cellar and listened to a local jazz band play some of his favorite tunes. Bill's students and colleagues shared their memories and stories about him.

Something I realized only after he was gone is that Bill had been a very happy, and always optimistic person. In closing, we should all remember that one of the many remarkable things about Bill is that he never expressed any regrets. He loved his life.

\section{References}

1. William ARveson, Subalgebras of $C^{*}$-algebras, Acta Math. 123 (1969), 141-224.

2. Subalgebras of $C^{*}$-algebras. II, Acta Math. 128 (1972), no. 3-4, 271-308.

3. J. Amer. Math. Soc. 21 (2008), no. 4, 1065-1084. 
4. _ The noncommutative Choquet boundary III: Operator systems in matrix algebras, Math. Scand. 106 (2010), no. 2, 196-210.

5. WILliAm B. ARVESON, Analyticity in operator algebras, Amer. J. Math. 89 (1967), 578-642.

6. DAVID P. BLECHER, ZHONG-JIN RUAN, and ALLAN M. SINCLAIR, A characterization of operator algebras, J. Funct. Anal. 89 (1990), no. 1, 188-201.

7. KENNETH R. DAVIDSON, The mathematical legacy of William Arveson, J. Operator Theory 68 (2012), no. 2, 307-334.

8. P. A. M. DIRAC, Statement of a problem in quantum mechanics, J. London Math. Soc. S1-8 (1926), no. 4, 274.

9. EDWARD G. EFFros and ZHONG-Jin RuAN, Operator Spaces, London Mathematical Society Monographs, New Series, vol. 23, The Clarendon Press, Oxford University Press, New York, 2000.

10. Bent Fuglede and RichaRd V. KADISOn, On determinants and a property of the trace in finite factors, Proc. Nat. Acad. Sci. U. S. A. 37 (1951), 425-431.

11. , Determinant theory in finite factors, Ann. of Math. (2) 55 (1952), 520-530.

12. J. HADAMARD, Résolution d'une question relative aux determinants, Bull. des Sciences Math. 17 (1893), 240246.

13. MASAKI IZUMI, $E_{0}$-semigroups: Around and beyond Arveson's work, J. Operator Theory 68 (2012), no. 2, 335-363.

14. RICHARD V. KADISON and I. M. SINGER, Triangular operator algebras. Fundamentals and hyperreducible theory, Amer. J. Math. 82 (1960), 227-259.

15. V. PAUlSEN et al., see arXiv.

16. GILlES PISIER, Introduction to Operator Space Theory, London Mathematical Society Lecture Note Series, vol. 294, Cambridge University Press, Cambridge, 2003.

17. ZHONG-Jin RuAN, Subspaces of $C^{*}$-algebras, J. Funct. Anal. 76 (1988), no. 1, 217-230.

18. BÉLA Sz.-NAGY, Sur les contractions de l'espace de Hilbert, Acta Sci. Math. Szeged 15 (1953), 87-92.

19. A. S. Wightman, Hilbert's sixth problem: Mathematical treatment of the axioms of physics, Mathematical Developments Arising from Hilbert Problems (Proc. Sympos. Pure Math., Northern Illinois Univ., De Kalb, Ill., 1974), Amer. Math. Soc., Providence, RI, 1976, pp. 147-240.

20. GERD WITTSTOCK, Ein operatorwertiger Hahn-Banach Satz, J. Funct. Anal. 40 (1981), no. 2, 127-150.

\section{)}

MATHEMATICI IMABEERS

\section{View and share \\ hundreds of images!}

The connection between

mathematics and art goes back

thousands of years. Mathematics

has been used in the design of

Gothic cathedrals, Rose windows,

oriental rugs, mosaics and tilings.

Geometric forms were fundamen-

tal to the cubists and many

abstract expressionists, and

award-winning sculptors have used topology as the

basis for their pieces. Dutch artist M.C. Escher repre-

sented infinity, Möbius bands, tessellations, deforma-

tions, reflections, Platonic solids, spirals, symmetry, and

the hyperbolic plane in his works.

Mathematicians and artists continue to create stunning works in all media and to explore the visualization of mathematics--origami, computer-generated landscapes, tessellations, fractals, anamorphic art, and more.

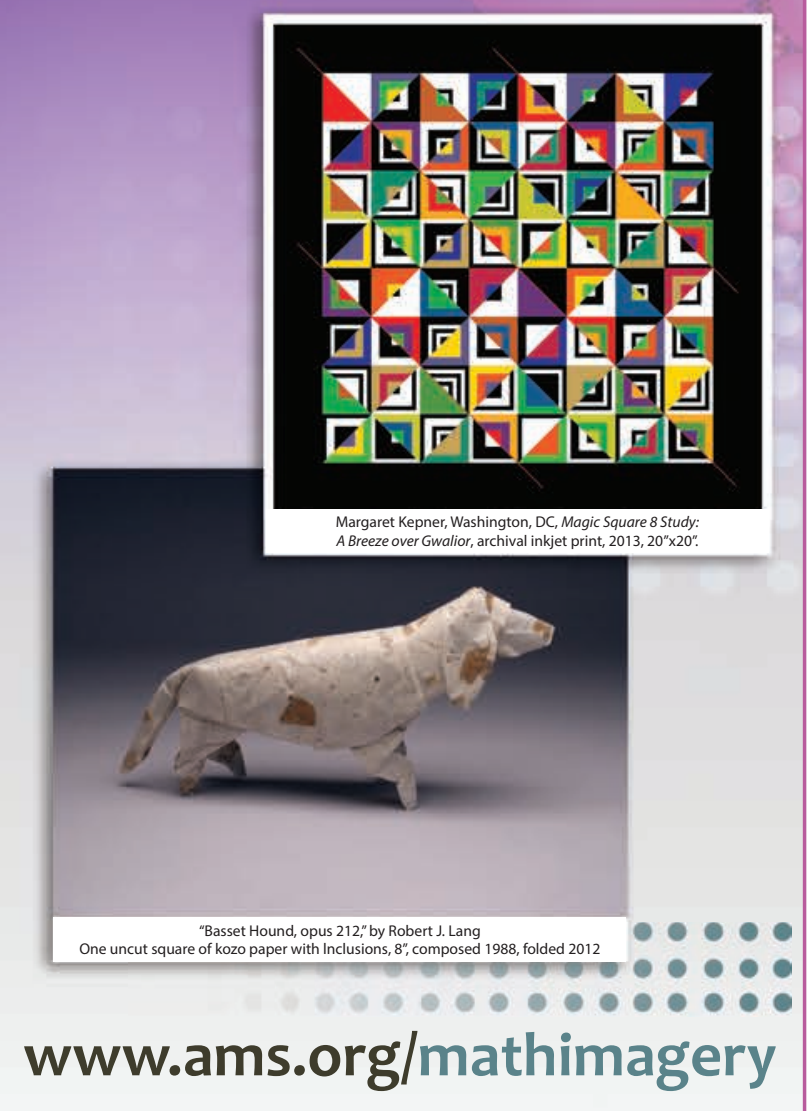

